\title{
An optimization procedure for the soil behavior identification using pressuremeter results
}

\author{
Younes Abed ${ }^{*}$ (1)
}

\author{
*Correspondence: \\ y.abed1967@univ-blida.dz \\ Department of Civil \\ Engineering, Faculty \\ of Technology, University \\ of Blida1, Route de Soumaa, \\ 09000 Blida, Algeria
}

\begin{abstract}
The soil parameters identification procedure is usually a trade-off between sophisticated soil model behaviour and the large number of parameters to identify. Such procedure that can accomplish both of these objectives is highly desirable, but also difficult. This paper presents a methodology for identifying soil parameters that takes into account different constitutive equations. For identifying the generalized Prager model parameters, associated to the Drucker and Prager failure criterion, using an in-situ pressuremeter curve, we have proposed a procedure that is based on an approach of inverse analysis. This approach involves the minimizing the function representing the area between the experimental curve and the simulated curve, obtained by fit in the model along the in-situ loading path. A comparative study between two optimization processes is proposed. The first is based on the technique of the simplex by Nelder and Mead, while the second is based on the decomposition of the pressuremeter curve in three distinct areas. After a brief description of an existing computer program called Press-Sim, which has been written in Fortran for analyzing a cavity expansion using the finite element method, a short explanation is given about the two optimization procedures considered in this article. Then, for a chosen site where soil strength parameters are measured, the comparative study has been performed for both methods at four different depths. For the determination of the angle of friction, the two procedures yield very close values and are in a good agreement with that given by the triaxial test, while for the cohesion, they both diverge from each other on both sides of the value measured by the trial test.
\end{abstract}

Keywords: Pressuremeter test, Finite element method, Cavity expansion, Simplex optimization, Cohesive soil, Inverse analysis

\section{Introduction}

The soil behaviour parameters are generally determined from laboratory tests, which are performed on the field samples. The quality of these tests depends on the quality of samples, which some conditions are not well controlled (disturbance, representativeness, initial conditions,...). It seems interesting or even essential to make this identification from in-situ tests. party material in this article are included in the article's Creative Commons licence, unless indicated otherwise in a credit line to the material. If material is not included in the article's Creative Commons licence and your intended use is not permitted by statutory regulation or exceeds the permitted use, you will need to obtain permission directly from the copyright holder. To view a copy of this licence, visit http:// creativecommons.org/licenses/by/4.0/. 
To overcome these difficulties, many of researches have been proposed to determine these parameters from in-situ tests. Among in-situ tests, the pressuremeter test, which is a common practice for foundation designing in all over the world and specially in North Africa, consists in studying the expansion of a cylindrical cavity within the soil. Pressuremeter test has the advantage of providing the geotechnical engineer with both a failure parameter (the limit pressure $P_{L}$ ) and a deformation parameter (the pressuremeter modulus $E_{p}$ ).

The pressuremeter can be used by two ways:

- The pressuremeter results are directly used in foundations design.

- The pressuremter curve is matching to a simulated curve to identify some soil behaviour parameters, such as, elastic modulus $(\mathrm{E})$, cohesion $(\mathrm{c})$, friction $(\phi), \ldots$

The soil parameters can be determinated from pressuremeter tests by using an inverse analysis of the cavity pressure-cavity strain relationship measured in the field. To perform this, the pressuremeter test is generally simulated as the expansion of an infinitely long cylindrical cavity inside an infinite uniform medium by means of closed-form analytical solutions $[1,2]$ or approached numerical models, such as the finite elements [3-19].

Engineers choose closed-form analytical solutions than numerical models because the choice of the numerical methods is often time consuming and computationally noneffective. However, the use of approximate numerical models becomes the only possible alternative, in the case where it is difficult to obtain a closed-form solution due to the difficulty of the soil constitutive model.

In addition, the most elasto-plastic models need the determination of a relatively large number of parameters, which makes empirical curve fitting unfeasible so that the use of optimization algorithms for matching simulations to experiments is necessary.

The purpose of the present work is to develop an effective and reliable procedure for the identification of the mechanical properties of soils by interpreting results from pressuremeter tests. More precisely, the paper presents a methodology for the identification of parameters values in the Generalized Prager Model (GPM), (the reader is referred to the papers by Abed and Bahar [20] and Abed et al. [21]) of the mechanical properties of soils by an inverse analysis of the experimental pressure-strain curve of an in-situ pressuremeter test. Two optimization techniques are presented,one is based on the simplex method of Nelder and Mead [22] and the other is based on the decomposition of the pressuremeter curve.

Examples of identification made on the Nogent pasty chalk [23] using both optimization techniques are presented and compared with other results (Duncan model, [23] and triaxial results). The influence of each parameter on the simulation quality and evolution of stresses around the pressuremeter drilling are also presented.

\section{Methodology}

The GP-DP models

The GP-DP (which stands for Generalized Prager associated with Drucker and Prager Models) is an elasto-plastic constitutive model for predicting the nonlinear stress-strain 


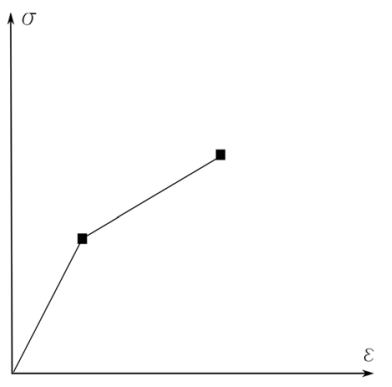

(a)

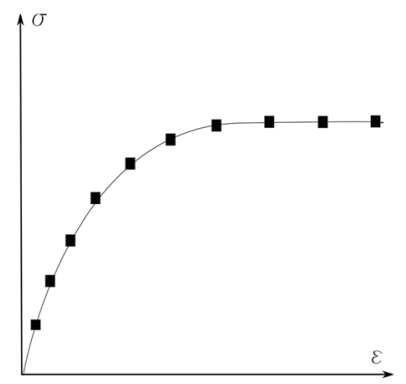

(b)

Fig. 1 Stress-strain relationships: a bilinear; b piecewise linear

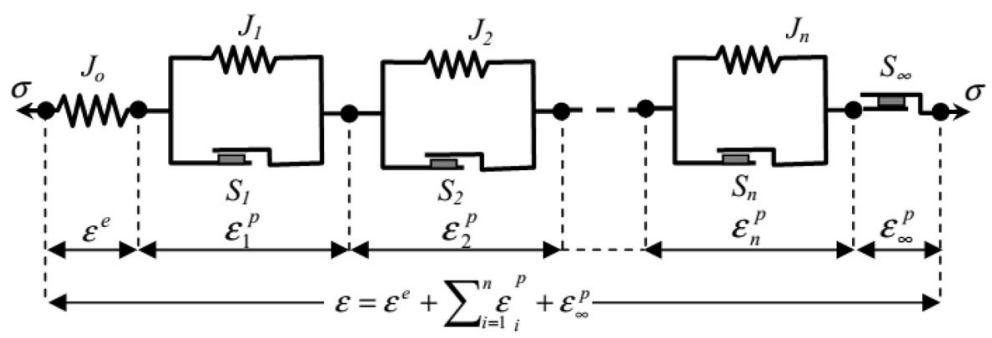

Fig. 2 Multiple surface model

behaviour of soils. Based on the use of a kinematic hardening function, a bilinear stressstrain behaviour can be simply described by means of a single internal variable (Fig. 1a). Considering the idea of kinematic hardening and multiple combined internal variables, a piecewise linear stress-strain response can be described (Fig. 1b). The stress-strain curve is modeled by linear segments along which the tangent shear modulus is assumed to be constant [24].

The model, based on a serial assemblage of several single Prager models is defined by the compliance of $(n)$ elastic elements and their associated $(n)$ yield surfaces. Finally, a single linear spring elastic element of compliance $\left(J_{0}\right)$ and a single yield surface of threshold stress $\left(S_{\infty}\right)$ can be introduced and connected in series to the collection of elements to represent the initial elastic strain and failure respectively (Fig. 2). Therefore, the model is defined by $(2 n+2)$ parameters that can be characterised by a discrete spectrum of compliance.

The assumed Kinematic hardening model, adopts that during the plastic deformation the loading surface translates as a rigid body in the stress space keeping the shape, orientation and size of the initial yield surface. The expression for the yielding surface is:

$$
f\left(\sigma_{i j}, \varepsilon_{i j}^{p}\right)=F\left(\sigma_{i j}-x_{i j}\right)-k^{2}
$$

where $k$ is a constant and $x_{i j}$ are the coordinates of the center of loading surface which changes as the development of plastic strains continues. The simplest version for determining the parameter $x_{i j}$ is to assume a linear dependence of $d x_{i j}$ : 


$$
d x_{i j}=C d \varepsilon_{i j}^{p}
$$

where $C$ is the work hardening constant, characteristic of a given material. Equation (2) may be taken as the definition of the linear work hardening.

The plastic strain is given by the normality rule (standard material)

$$
\begin{aligned}
& \left(d \varepsilon_{i j}^{p}\right)^{k}=\left(\frac{\partial f}{\partial \sigma_{i j}}\right) d \lambda_{k} \\
& \left(d \varepsilon_{i j}^{p}\right)^{k}=0 \text { if } \quad d \sigma_{i j} n_{i j} \leq 0 .
\end{aligned}
$$

The consistency condition means that the yield surface keeps the same radius, this helps to determine the plastic proportionality factor $d \lambda$ with:

$$
d \lambda_{k}=\frac{1}{C_{k}} \frac{\frac{\partial f}{\partial \sigma_{i j}} d \sigma_{i j}}{\left(\frac{\partial f}{\partial \sigma_{k l}}\right)\left(\frac{\partial f}{\partial \sigma_{k l}}\right)}>0,
$$

where the underscript $k$ denotes the $k$ th element of chain; $C_{k}$ is the modulus of the kth element of the chain; $n_{i j}^{k}$ is the normal external vector to the yield surface.

\section{Yield function and plastic flow rule}

The Drucker and Prager failure criterion [25] is associated with the Generalised Prager model. For this criterion, it is assumed that the octahedral shear stress at failure depends linearly on the octahedral normal stress through material constants. The Drucker and Prager criterion is matched to the Mohr-Coulomb criterion by:

$$
\sqrt{J_{2}}=\alpha I_{1}+K
$$

where the constants $\alpha$ and $K$ are material constants.

$J_{2}$ is the second invariant of the stress deviator tensor and $I_{1}$ is the first invariant of the stress tensor, and are defined as follows:

$$
\begin{aligned}
& I_{1}=\sigma_{1}^{\prime}+\sigma_{2}^{\prime}+\sigma_{3}^{\prime}, \\
& J_{2}=\frac{1}{6}\left[\left(\sigma_{1}^{\prime}-\sigma_{2}^{\prime}\right)+\left(\sigma_{3}^{\prime}-\sigma_{1}^{\prime}\right)+\left(\sigma_{2}^{\prime}-\sigma_{3}^{\prime}\right)\right],
\end{aligned}
$$

$\sigma_{1}^{\prime}, \sigma_{2}^{\prime}, \sigma_{3}^{\prime}$, are the principal effective stresses.

The parameters $\alpha$ and $K$ can be calibrated to make the Drucker-Prager criterion fit different parts of the Mohr-Coulomb criterion [26]. The Mohr-Coulomb criterion and two different Drucker-Prager fits are shown in Fig. 3.

The two fits are:

1. Triaxial extension fit: The triaxial extension corners of the Mohr-Coulomb criterion coincide with the Drucker-Prager criterion. 


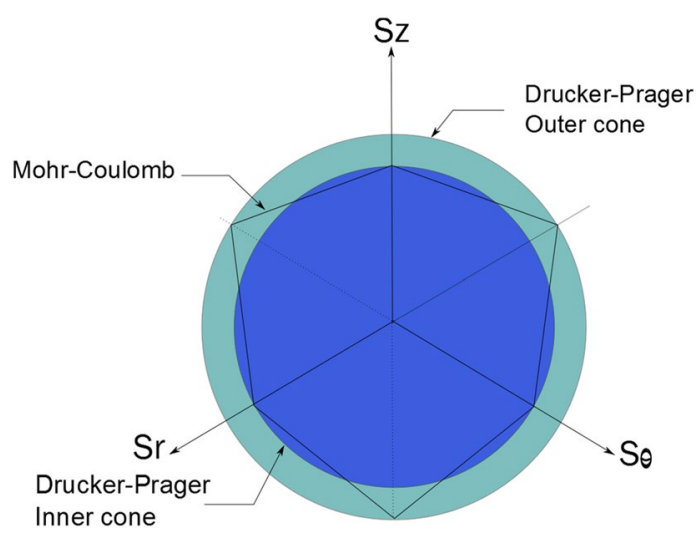

Fig. 3 Mohr-Coulomb and Drucker-Prager criteria on the octahedral plane

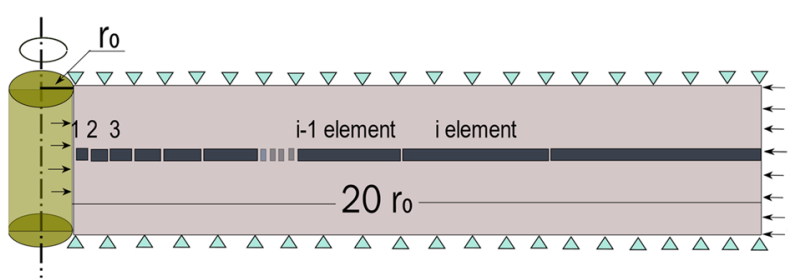

Fig. 4 Finite element mesh around pressuremeter borehole

2. Triaxial compression fit: The triaxial compression corners of the Mohr-Coulomb criterion coincide with the Drucker-Prager criterion.

\section{Finite element simulation of pressuremeter test}

In this work, the computed cavity pressure-cavity strain curves were obtained from the finite element simulation of an infinitely long cylindrical cavity expanding inside a cohesionless soil.

In order to apply the finite element method, the 1D expansion of an infinitely long cylindrical cavity is simulated. The segment $\left(r_{0}-r_{\infty}\right)$ is divided into $n$ segments of unequal lengths (Fig. 4). To ensure a good accuracy of stresses and strains, the mesh is relatively fine in the vicinity of the borehole. With growing distance to the probe, the elements increase progressively in size. With reference to the middle point of the Pressuremeter membrane, the dimension of the finite element mesh used is $20 r_{0}$ in width. The soil around the probe is modelled using a linear mesh [21].

\section{Solution of the problem in elastic zone}

In elasticity, the analytical solution of the differential equation governing the expansion of a cylindrical cavity is given according to the elastic parameters [27]:

$$
d \varepsilon_{r}=\frac{r_{0}}{r^{2}} d U_{0} \quad d \varepsilon_{\theta}=-\frac{r_{0}}{r^{2}} d U_{0} \quad d \varepsilon_{z}=0,
$$




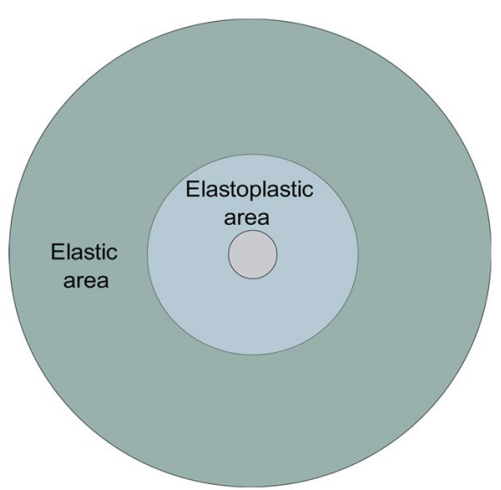

Fig. 5 Yield zone around the expanding cavity

$$
d \sigma_{r}=\frac{E}{1+v} \frac{r_{0}}{r^{2}} d U_{0} \quad d \sigma_{\theta}=-\frac{E}{1+v} \frac{r_{0}}{r^{2}} d U_{0} \quad d \sigma_{z}=0
$$

The deformation occurs at a constant stress without volume changes, as shown in Fig. 5.

\section{Solution of the problem in elasto-plastic zone}

The behaviour law can be written by:

$$
d \varepsilon_{i j}=A_{i j k l} d \sigma_{k l}
$$

where the matrix $A_{i j k l}$ is function of the stress state and the loading path. It describes the soil behaviour for a loading increment. It may be written as:

$$
\begin{aligned}
& A_{i j}=-\frac{v}{E}+\sum_{k=1}^{n^{*}} \frac{J_{k}}{S_{k}^{2}}\left(\alpha+\frac{1}{4 J_{2}}\right)\left(S_{i}-X_{i}(k)\right)\left(S_{j}-X_{j}(k)\right) \text { For } i \neq j, \\
& A_{i j}=-\frac{1}{E}+\sum_{k=1}^{n^{*}} \frac{J_{k}}{S_{k}^{2}}\left(\alpha+\frac{1}{4 J_{2}}\right)\left(S_{i}-X_{i}(k)\right)\left(S_{j}-X_{j}(k)\right) \text { For } i=j .
\end{aligned}
$$

\section{Identifying GP-DP models parameters from pressuremeter test}

The general framework adopted in this paper for the calibration of the GP-DP models from pressuremeter tests is first described in this section. The two main components of the proposed methodology are the finite element simulation of pressuremeter tests and the optimization algorithm.

The flowchart showed in Fig. 6 explains the algorithm for inverse analysis of pressuremeter test results. The flowchart starts from the consideration of two different pieces of information: on one side, there is a set of experimental pressure-expansion curve measured during in-situ pressuremeter test while, on the other side, there is a corresponding set of finite element simulations [28]. 


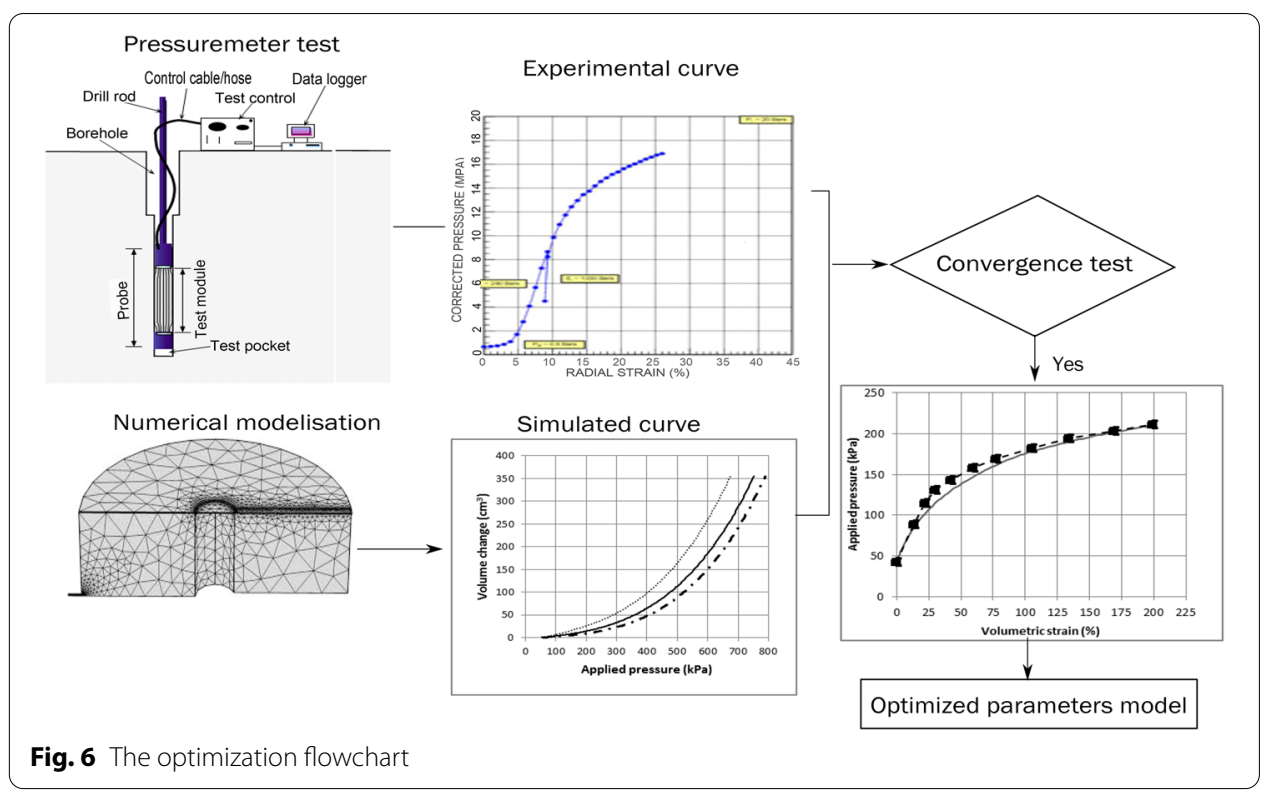

On the basis of the theoretical developments presented in the previous sections and subsections, a computer program called Press-Sim has been written in Fortran. As an input data, this program begins by reading geometrical parameters relative to the Finite Element mesh and soil properties in order to establish a computed pressure curve at a given depth. In addition to data required for the simulation, Press-Sim necessitates the experimentally established pressuremeter curve at the same depth. Generally speaking, this computer program carries fundamentally two main tasks. The first consists in the establishment of a numerical curve illustrating the variation of volume changes $((\Delta V)$ in function of the applied pressure $((P)$, while the second is the matching of the computed and the experimental curves according to a specifically chosen optimization procedure. These two tasks lead finally to the determination of soil parameters namely: elastic modulus, $E$, cohesion, $c$, friction angle, $\varphi$ and curvature coefficient, $\beta$ which can be considered as the results of the best fit of the two curves [28].

The determination of the parameter values in constitutive models from the pressuremeter test consists in finding a set of parameters which minimizes the discrepancy between the experimental and the simulated curves. This problem is classically defined by an objective function which reveals, for a given set of parameters, the discrepancy between the model prediction and the experimental data. In other words, the goal is to find the curve that better matches the experimental curve. In Press-Sim two optimization processes have been incorporated; the Nelder and Mead simplex method and another method called 'Curve decomposition method' (for more details see [21]).

\section{Nelder and Mead simplex method}

This algorithm iterates on a simplex, which is a set of $n+1$ designs, $(p(1), p(2), \ldots, p(n+1))$. The Nelder-Mead algorithm specifies a sequence of steps for 


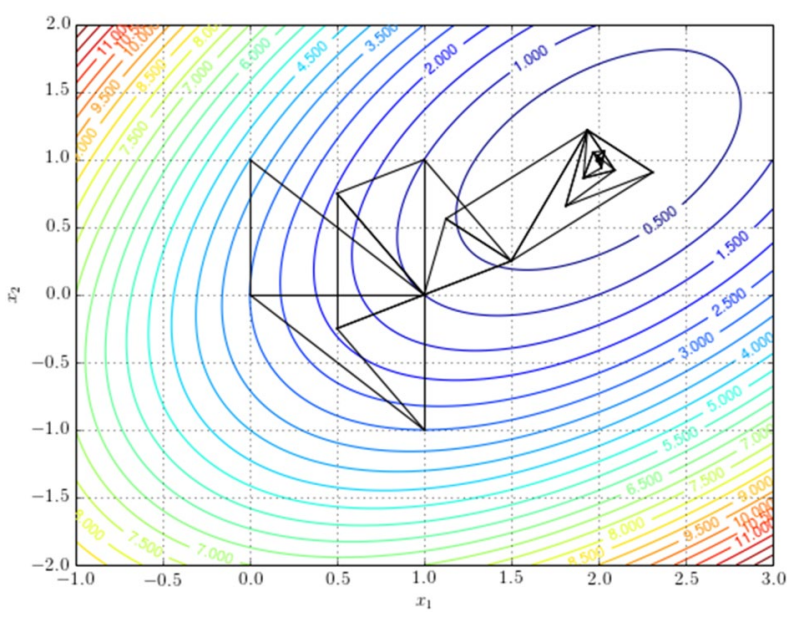

Fig. 7 Evolution process for two parameters case
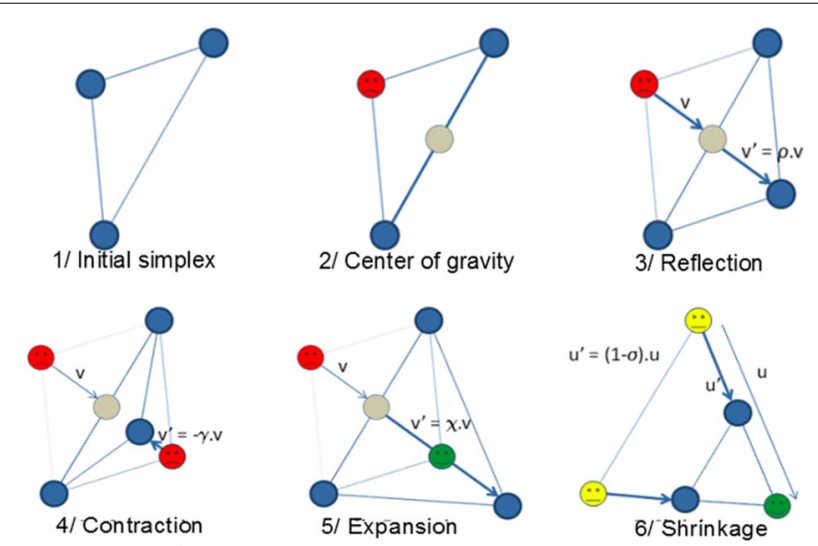

Fig. 8 Sequence of steps in one iteration of the Nelder-Mead method

iteratively updating the worst design in the simplex $(p(n+1))$ in order to converge on the smallest value of $(p(1))$ (Fig. 7).

The simplex may be thought of as a polygon with $(n+1)$ vertices. If $(n=2)$, the simplex is a triangle, and the Nelder-Mead algorithm may be easily visualized. In this paper, we introduce the Nelder-Mead algorithm for triangular simplexes.

Consider a simplex of three points $(i, j, k)$ in the $p 1-p 2$ plane, the triangle connecting them, and the objective function $f$ evaluated at the three points, $f(i), f(j)$ and $f(k)$. The steps listed below, and illustrated in Fig. 8, exhibit an iterative process which improves the vertices of the triangle in order to minimize the objective function.

\section{Curve decomposition method}

The simultaneous identification of the parameters E, c, $\phi$ and $\beta$, from one pressuremeter test carried out leads to erroneous estimates, even if the numerical predictions perfectly fit the experimental data. In this case, additional experimental information is therefore 


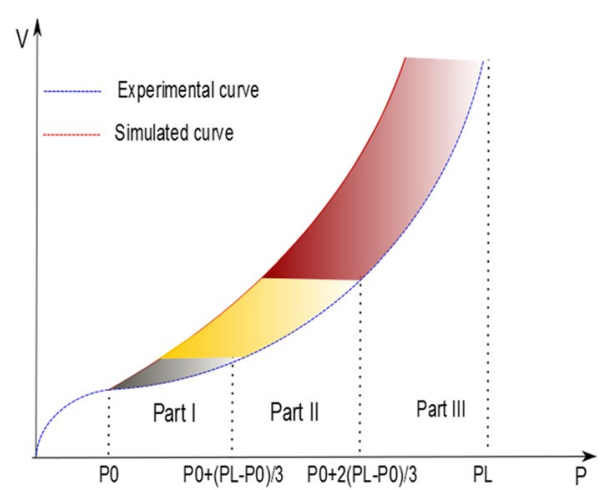

Fig. 9 Subdivision of the pressuremeter curve in the decomposition method

Table 1 Mechanical characteristics of pasty chalk of Nogent-sur-Seine (France)

\begin{tabular}{llcc}
\hline Depth $(\mathbf{m})$ & Specific weights, $\boldsymbol{\gamma}_{\boldsymbol{d}}\left(\mathbf{k N} / \mathbf{m}^{\mathbf{3}}\right)$ & Cohesion, $\boldsymbol{c}(\mathbf{k P a})$ & $\begin{array}{l}\text { Friction } \\
\text { angle, } \boldsymbol{\varphi}\left({ }^{\circ}\right)\end{array}$ \\
\hline 10.50 & 14.00 & 100 & 33 \\
11.50 & 14.43 & 75 & 33 \\
12.50 & 16.64 & 84 & 33 \\
13.50 & 16.59 & 47 & 36 \\
\hline
\end{tabular}

required to improve the optimization process. The Curve decomposition method consists of subdividing the pressuremeter curve into three parts (Fig. 9). The first one describes the small strains (pressures belonging to the range $\left(P_{0}, P_{0}-\left(P_{\mathrm{L}}-P_{0}\right) / 3\right)$. This part characterizes the deformability of the soil (the Young's modulus $E$ and the Poisson's ratio $v)$. The second part, which defines the pressures ranging from $P_{0}-\left(P_{\mathrm{L}}-P_{0}\right) / 3$ to $P_{0}-2\left(P_{\mathrm{L}}-P_{0}\right) / 3$, characterizes the curvature of the pressuremeter curve and consequently it is closely related to the parameter $\beta$.

The pressures belonging to the third part (part III) vary from $P_{0}-2\left(P_{\mathrm{L}}-P_{0}\right) / 3$ to the limit pressure $P_{L}$. This part called zone of large strains, characterizes the failure behaviour of the cohesive soil (friction angle $\varphi$ and cohesion $c$ ) [21].

\section{Results and discussion}

Identification examples

In order to show the difference between the two optimization processes, we considered first the site of Nogent-sur-Seine (France), which consists of a deep layer of pasty chalk, through which a borehole has been performed and samples were extracted for laboratory testing. Specific weights and strength parameters namely $c$ and $\varphi$ were measured at four different depths. The measured characteristics are shown on Table 1 [29].

\section{Computed against experimental results}

Figures 10, 11, 12 and 13 show the experimentally determined pressumeter curves along with those obtained using the computer program Press-Sim. In order to gain a better 


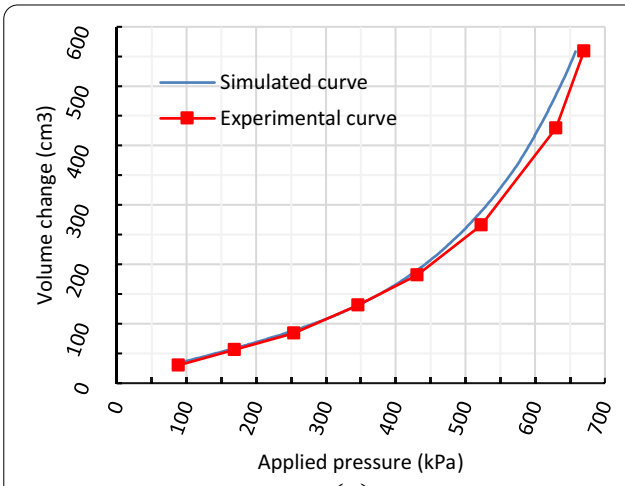

(a)

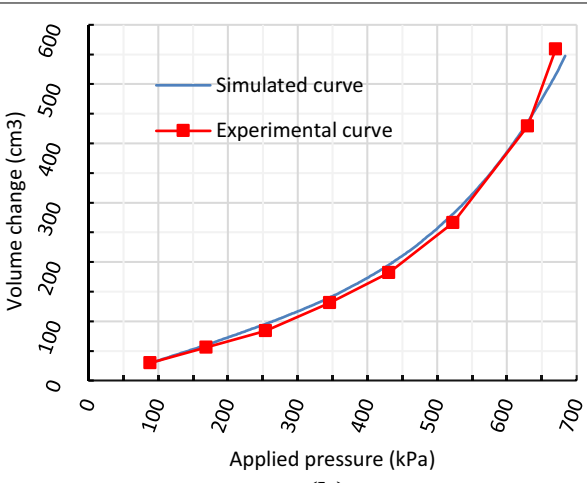

(b)

Fig. 10 Experimental against simulated curves at depth of $10.5 \mathrm{~m}$, a simplex method, $\mathbf{b}$ curve decomposition method

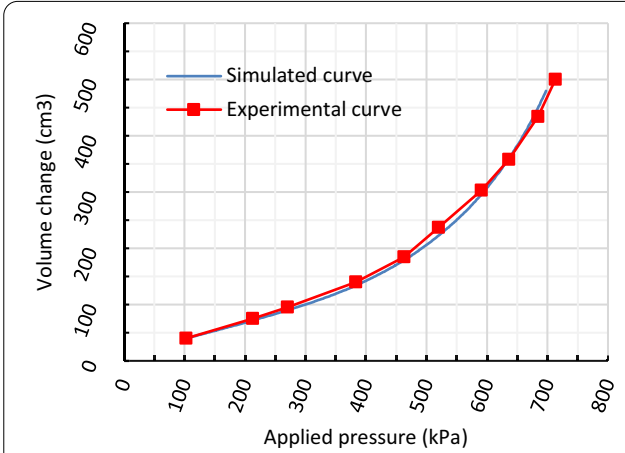

(a)

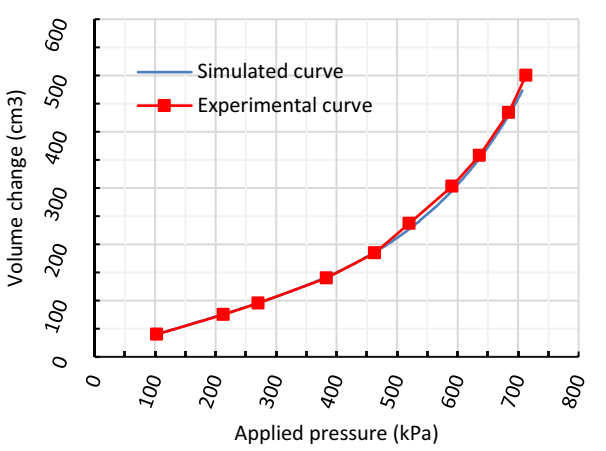

(b)

Fig. 11 Experimental against simulated curves at depth of $11.5 \mathrm{~m}$, a simplex method, $\mathbf{b}$ curve decomposition method

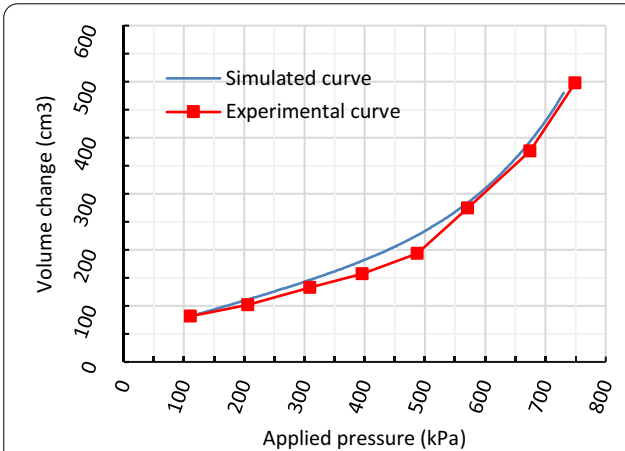

(a)

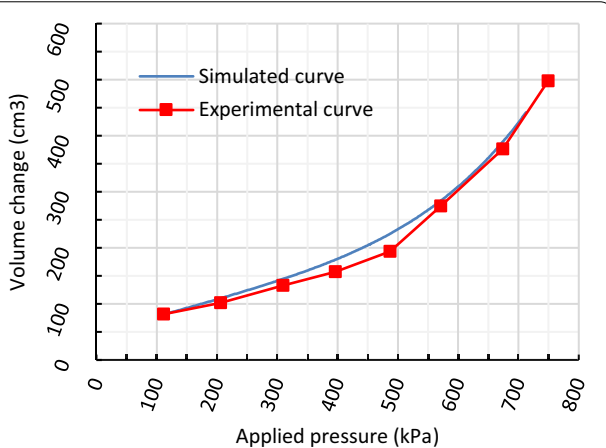

(b)

Fig. 12 Experimental against simulated curves at depth of $12.5 \mathrm{~m}$, a simplex method, $\mathbf{b}$ curve decomposition method

understanding and to have a clear vision for comparison, two graphs relevant to the optimization processes are plotted in each Figure. 


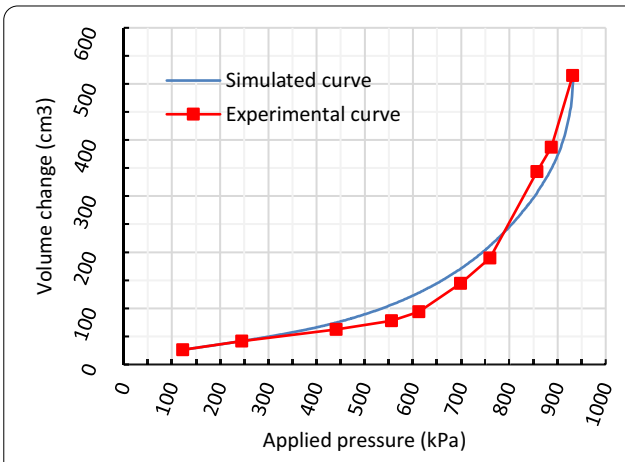

(a)

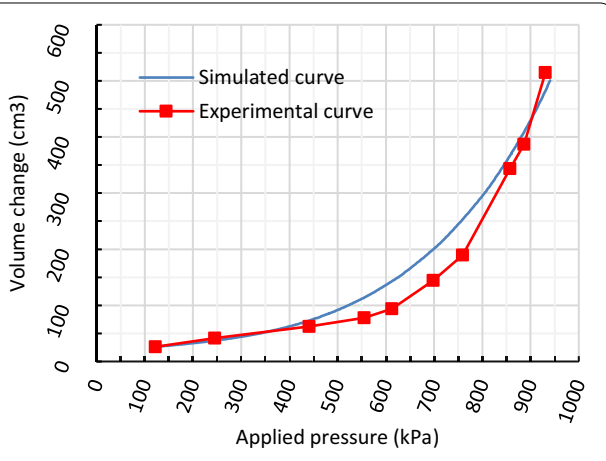

(b)

Fig. 13 Experimental against simulated curves at depth of $13.5 \mathrm{~m}$, a simplex method, $\mathbf{b}$ curve decomposition method

Table 2 Simulation results for various values of $\varphi$ at different depths

\begin{tabular}{|c|c|c|c|c|c|c|c|}
\hline \multirow[t]{2}{*}{$\operatorname{Depth}(\mathrm{m})$} & \multirow[t]{2}{*}{$\varphi\left({ }^{\circ}\right)$} & \multicolumn{3}{|c|}{ Decomposition method } & \multicolumn{3}{|c|}{ Simplex method } \\
\hline & & $E(\mathrm{kPa})$ & $\beta\left(10^{-2}\right)$ & $c(\mathrm{kPa})$ & $E(\mathrm{kPa})$ & $\beta\left(10^{-2}\right)$ & $c(\mathrm{kPa})$ \\
\hline \multirow{4}{*}{10.50} & 15 & 25,532 & 2.81 & 192 & 23,105 & 2.12 & 197 \\
\hline & 20 & 25,716 & 3.12 & 149 & 31,724 & 2.85 & 125 \\
\hline & 25 & 25,468 & 3.22 & 117 & 30,912 & 2.29 & 102 \\
\hline & 30 & 25,354 & 3.30 & 97 & 31,352 & 2.53 & 85 \\
\hline \multirow[t]{4}{*}{11.50} & 15 & 30,225 & 1.77 & 190 & 25,721 & 1.15 & 207 \\
\hline & 20 & 29,753 & 1.81 & 145 & 28,130 & 0.92 & 137 \\
\hline & 25 & 28,961 & 1.92 & 115 & 82,925 & 0.97 & 105 \\
\hline & 30 & 28,732 & 2.11 & 95 & 29,176 & 0.83 & 82 \\
\hline \multirow[t]{4}{*}{12.50} & 15 & 31,562 & 2.81 & 225 & 32,305 & 1.73 & 207 \\
\hline & 20 & 31,458 & 2.86 & 168 & 30,271 & 0.91 & 147 \\
\hline & 25 & 31,482 & 2.91 & 131 & 29,026 & 0.96 & 121 \\
\hline & 30 & 32,530 & 1.29 & 89 & 30,562 & 1.21 & 98 \\
\hline \multirow[t]{4}{*}{13.50} & 15 & 103,121 & 2.74 & 294 & 73,224 & 6.52 & 258 \\
\hline & 20 & 102,725 & 2.81 & 227 & 80,721 & 7.22 & 187 \\
\hline & 25 & 98,756 & 2.87 & 184 & 78,623 & 8.13 & 151 \\
\hline & 30 & 98,123 & 2.93 & 147 & 90,230 & 7.70 & 117 \\
\hline
\end{tabular}

A close examination of Figs. 10 and 11, which illustrate the variation of volume changes $(\Delta V)$ with the applied pressure $(P)$ at respectively $10.5 \mathrm{~m}$ and $11.5 \mathrm{~m}$ in depth, makes it clear that the curve related to the decomposition method yields better results as the curves are fully matched. A slight discrepancy is observed in the last values for the simplex curves. However, in Figs. 12 and 13 the optimization curves for both methods deviate slightly from those of pressuremeter in values ranging approximately between 400 and $800 \mathrm{kPa}$. This discrepancy, as we can see, can be explained by the poor quality of experimental results in this interval of the curve. The obtained parameters from the simulations performed at the four considered depths are illustrated in Table 2.

The two proposed approaches, in term of failure parameters (c and $\phi$ ) give some divergences. This can be explained by the optimization technique of each method; the 
simplex method optimizes the three parameters (E, $\beta$ and $c)$ simultaneously. While, the curve decomposition method optimizes each parameter on its influence area.

\section{Practical application for determining the cohesion and the friction angle}

The two parameters that characterize the behaviour in large strains are the cohesion $c$ and friction angle $\varphi$. Their simultaneous identification may lead to different pairs of $c$ and $\varphi$ values that allow good calibration of the experimental curve to the simulated curve. If no further information is provided, and if only one test is available, it will not be possible to identify both $c$ and $\varphi$. However, the identification of two parameters will be possible if we have at least two pressuremeter tests carried out on the same material, at two significantly different depths.

The identified pair values for each method at depths of $10.5 \mathrm{~m}, 11.5 \mathrm{~m}$ and $11.5 \mathrm{~m}$ are represented on the same graph by linear adjustment $(c=a+b \varphi)$ using the method of least squares. The couple $\mathrm{c}$ and $\phi$, selected corresponds to that which belongs to the two adjustments. Figures 14 and 15 shows the results retained in this case, as shown in Table 3.
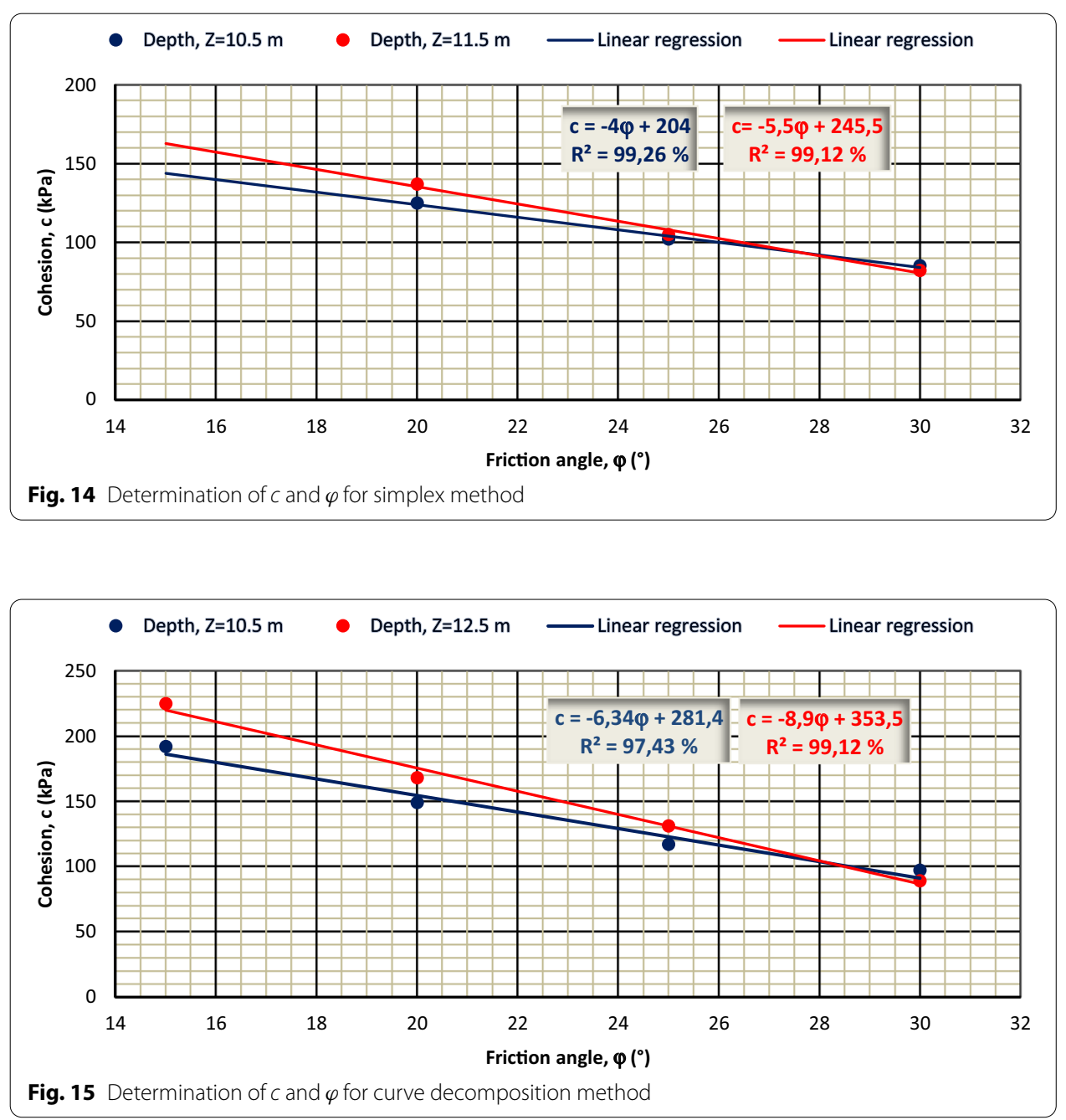
Table 3 Couples of values $(c, \varphi)$ for the site "Nogent-sur-Seine, France"

\begin{tabular}{|c|c|c|c|c|}
\hline \multirow[t]{3}{*}{$\varphi\left({ }^{\circ}\right)$} & \multicolumn{4}{|c|}{ Cohesion $c(\mathrm{kPa})$} \\
\hline & \multicolumn{2}{|c|}{ Simplex method } & \multicolumn{2}{|c|}{ Decomposition curve method } \\
\hline & $z=10.5 \mathrm{~m}$ & $z=11.5 \mathrm{~m}$ & $z=10.5 \mathrm{~m}$ & $z=12.5 \mathrm{~m}$ \\
\hline 15 & 197 & 207 & 192 & 225 \\
\hline 20 & 125 & 137 & 149 & 168 \\
\hline 25 & 102 & 105 & 117 & 131 \\
\hline 30 & 85 & 82 & 97 & 89 \\
\hline$R^{2}(\%)$ & 99.12 & 99.26 & 97.43 & 99.12 \\
\hline
\end{tabular}

Table 4 Couple of values $(c, \varphi)$ of the site "Nogent-sur-Seine" for triaxial test and different methods

\begin{tabular}{|c|c|c|c|c|c|c|c|}
\hline \multicolumn{2}{|c|}{ Simplex method } & \multicolumn{2}{|c|}{$\begin{array}{l}\text { Curve decomposition } \\
\text { method }\end{array}$} & \multicolumn{2}{|c|}{ Duncan-Chang model } & \multicolumn{2}{|c|}{ Triaxial test } \\
\hline$c(\mathrm{kPa})$ & $\varphi\left({ }^{\circ}\right)$ & $c(\mathrm{kPa})$ & $\varphi\left({ }^{\circ}\right)$ & $c(\mathrm{kPa})$ & $\varphi\left({ }^{\circ}\right)$ & $c(\mathrm{kPa})$ & $\varphi\left({ }^{\circ}\right)$ \\
\hline 100 & 28 & 103 & 28 & 145 & 31 & 86 & 33 \\
\hline
\end{tabular}

Table 4 shows $c$ and $\varphi$ pairs obtained for the depths $10.5 \mathrm{~m}$ and $12.5 \mathrm{~m}$ using a curve decomposition method.

From Table 4, it is clearly seen, that the two procedures yield same values of cohesion and close values of friction angle and are in a good agreement with that given by the triaxial test.

The identified parameters from the present approach seem to lead to a comparable result to those deduced from the triaxial test.

\section{Conclusion}

In this paper, a combined numerical/experimental approach which consists of minimizing the function representing the difference between the experimental curve and the curve obtained by integrating the model along the loading path in the in-situ testing has been presented. This problem is classically defined by an objective function which reveals, for a given set of parameters, the discrepancy between the model prediction and the experimental data. In other words, the purpose is to find the curve that better matches the experimental curve.

In this article, two optimization procedures have been proposed:

- The first is based on a simplex optimization algorithm of Nelder and Mead.

- The second employs the decomposition of the pressuremeter curve in three parts, where each set of parameters is assigned to a part for the determination of its appropriate parameters.

The simplex method of Nelder and Mead is a very general optimization method, which evaluates the minimum of a function dependent on several parameters. Although, this method is very general as it does not take into account the specificities of the pressuremeter test, it proves its effectivity for the determination of parameters characterizing the model.

The second method, most interesting is a method that accounts for the particular aspects of the pressuremeter test. It identifies the parameters on the part of the curve for which these parameters are relevant and they prove to be the most sensitive. 
The proposed approach for the determination of parameters that have the same effect on the pressuremeter curve (c and $\phi$ ) seems give a reasonable result. However, its generalisation to other soil types, needs to be validated by more examples. This could be the limitation of the application of the proposed inverse analysis procedure.

Finally, the values of the model parameters, especially, the friction angle is quite close to that deduced from the triaxial tests.

Received: 28 September 2020 Accepted: 15 June 2021

Published online: 22 November 2021

\section{References}

1. Rashed A, Bazaz JB, Alavi AH (2012) Nonlinear modeling of soil deformation modulus through LGP-based interpretation of pressuremeter test results. Eng Appl Artif Intell 25:1437-1449

2. Mousavi SM, Alavi AH, Mollahasani A, Gandomi AH (2011) A hybrid computational approach to formulate soil deformation moduli obtained from PLT. Eng Geol 123:324-332

3. Al-Zubaidi RM (2015) A new approach for interpretation strength sensitivity to in pressuremeter testing. Arab J Geosci 33(4):813-832

4. Cambou B, Boubanga A, Bozetto P, Haghgou M (1990) Determination of constitutive parameters from pressuremeters tests. In: 3rd Symp. pressuremeter and its marine applications, Oxford University, pp 243-352

5. Carter JP, Booker JR, Yeung SK (1986) Cavity expansion in frictional cohesive soils. Géotechnique 36(3):349-358

6. Cudmani R, Osinov VA (2001) The cavity expansion problem for the interpretation of cone penetration and pressuremeter tests. Can Geotech J 38(3):622-638

7. Fahey M, Carter JP (1993) A finite element study of the pressuremeter test in sand using a nonlinear elastic plastic model. Can Geotech J 30(2):348-362

8. Hsieh YM, Whittle AJ, Yu HS (2002) Interpretation of pressuremeter tests in sand using advanced soil model. ASCE J Geotech Geoenviron Eng 128(3):274-278

9. Javadi AA, Rezania M (2009) Applications of artificial intelligence and data mining techniques in soil modelling. Geomech Eng 01:53-74

10. Levasseur S (2008) Soil parameter identification using a genetic algorithm. Int J Numer Anal Methods Geomech 32(2):189-213

11. Levasseur S, Malecot Y, Boulon M, Flavigny E (2010) Statistical inverse analysis based on genetic algorithm and principal component analysis: applications to excavation problems and pressuremeter tests. Int J Numer Anal Methods Geomech 34:471-491

12. Liang RY, Sharo A (2010) Numerical investigation of the pressuremeter results affected by anisotropy of geomaterials. In: GeoFlorida 2010: advances in analysis, modeling \& design, pp 1090-1098

13. Olivari G, Bahar R (1995) Response of generalized Prager's model on pressuremeter path. In: Proceedings of the 4th international symposium on pressuremeters, A. A. Balkema, Sherbrooke, Canada, pp 207-213

14. Shahin MA, Jaksa MB, Maier HR (2008) State of the art of artificial neural networks in geotechnical engineering. Electron J Geotech Eng 8:1-26

15. Yu HS, Houlsby GT (1991) Finite cavity expansion in dilatant soils: loading analysis. Géotechnique 41(2):173-183

16. Yu HS, Houlsby GT (1995) A large strain analytical solution for cavity contraction in dilatant soils. Int J Numer Anal Methods Geomech 19(11):793-811

17. Zanier F (1985) Analyse numérique de l'essai pressiométrique par la méthode des éléments finis-Application au cas des sols cohérents. Thèse de Docteur-Ingénieur, Ecole Centrale de Lyon, France

18. Zhang Y, Gallipoli D, Augarde CE (2009) Simulation-based calibration of geotechnical parameters using parallel hybrid moving boundary particle swarm optimization. Comput Geotech 36:604-615

19. Zhang Y, Gallipoli D, Augarde C (2013) Parameter identification for elasto-plastic modelling of unsaturated soils from pressuremeter tests by parallel modified particle swarm optimization. Comput Geotech 48:293-303

20. Abed Y, Bahar R (2010) Pressuremeter identification procedure based on generalised Prager model. Medwell J Eng Appl Sci 5(2):50-55

21. Abed Y, Bahar R, Dupla J-C, Amar Bouzid DJ (2014) Identification of granular soils strength and stiffness parameters by matching finite element results to PMT data. Int J Comput Methods 2(2):231-253

22. Nelder J, Mead R (1965) A simplex method for function minimization. Comput J 7(4):308-313

23. Boubanga A (1990) Identification de paramètres de comportement des sols à partir de l'essai préssiométrique. Thèse de Doctorat, Ecole Centrale de Lyon, France

24. Bahar R, Abed Y, Olivari G (1999) Theoretical analysis of the behavior of clays around pressuremter. In: Proc. 12th Regional Conf. Africa on Soil Mech. Geotech. Eng. Durban, South Africa, pp 135-141

25. Drucker DC, Prager W (1952) Soil mechanics and plastic analysis on limit design. J Appl Math 10:157-165

26. Chen WF, Mizuno E (1990) Non linear analysis in soil mechanics, theory and implementation. Elsevier, Amesterdam

27. Clarke BG (1995) Pressuremeters in geotechnical design. Blackie Academic and Professional, London

28. Abed Y, Amar Bouzid DJ, Bahar R, Toumi I (2016) Parameters identification of granular soils around PMT tests by inverse analysis. In: Advances in civil, environmental, and materials research world congress (ACEM 16). Jeju island, Korea, August 28-Septembre 1, 2016

29. Sigismond J, Dupas JM, Lefebvre A (1983) La craie à Nogent-sur-Seine. Rev Fr Géotech 23:5-17 


\section{Publisher's Note}

Springer Nature remains neutral with regard to jurisdictional claims in published maps and institutional affiliations.

Submit your manuscript to a SpringerOpen ${ }^{\circ}$ journal and benefit from:

- Convenient online submission

- Rigorous peer review

- Open access: articles freely available online

- High visibility within the field

- Retaining the copyright to your article

Submit your next manuscript at $\boldsymbol{\nabla}$ springeropen.com 